\title{
Clinical value of SPECT/CT in the painful total knee arthroplasty (TKA): a prospective study in a consecutive series of 100 TKA
}

\author{
Michael T. Hirschmann ${ }^{1}$ • Felix Amsler ${ }^{2}$ Helmut Rasch ${ }^{3}$
}

Received: 25 February 2015 / Accepted: 21 May 2015 /Published online: 6 June 2015

(C) Springer-Verlag Berlin Heidelberg 2015

\begin{abstract}
Purpose Bone single photon emission computed tomography (SPECT)/CT is considered as beneficial in unhappy patients with pain, stiffness or swelling after total knee arthroplasty (TKA). The purpose of this study was to identify typical patterns of bone tracer uptake (BTU), distribution and intensity values in patients after TKA. The above findings were correlated with the type and fixation of TKA, the time from TKA and intraoperative findings at revision surgery.

Methods A total of 100 knees of 84 consecutive patients (mean age \pm SD $70 \pm 11$ years) after TKA with persistent knee pain were prospectively included. All patients underwent clinical examination, standardized radiographs and ${ }^{99 \mathrm{~m}} \mathrm{Tc}-$ hydroxymethane diphosphonate (HDP) SPECT/CT as part of a routine diagnostic algorithm. The diagnosis before and after SPECT/CT and final treatment were recorded. TKA component position was determined on 3-D reconstructed images. Intensity and anatomical distribution of BTU was determined. Maximum intensity values were recorded as well as ratios in relation to the proximal midshaft of the femur. Univariate analyses (chi-square test, Pearson's correlation and $t$ test for independent samples) were performed $(p<0.05)$.

Results SPECT/CT changed the clinical diagnosis and final treatment in 85/100 (85 \%) knees. Intraoperative findings
\end{abstract}

Michael T. Hirschmann

Michael.Hirschmann@unibas.ch

1 Department of Orthopaedic Surgery and Traumatology, Kantonsspital Baselland (Bruderholz, Liestal, Laufen), 4101 Bruderholz, Switzerland

2 Amsler Consulting, Basel, Switzerland

3 Institute of Radiology and Nuclear Medicine, Kantonsspital Baselland, 4101 Bruderholz, Switzerland confirmed the preoperative SPECT/CT diagnosis in 32/33 knees $(97 \%)$. TKA loosening as well as progression of patellofemoral osteoarthritis (OA) was correctly diagnosed in $100 \%$ of knees. Typical patterns of BTU for specific pathologies were identified. Loose femoral TKA components significantly correlated with increased BTU at the lateral femoral regions $(p<0.05)$. Loose tibial TKA components significantly correlated with increased BTU at all tibial regions $(p<0.05)$ and around the tibial peg $(p>0.01)$.

Conclusion The diagnostic benefits of SPECT/CT in patients after TKA have been proven. Typical pathology-related BTU patterns were identified, which will improve reporting quality. Due to the benefits in establishing the correct diagnosis, SPECT/CT should be part of the routine diagnostic algorithm for patients with pain after TKA.

Keywords Knee · SPECT/CT - SPECT · CT · Total knee arthroplasty $\cdot$ Replacement $\cdot$ Component position $\cdot$ Tracer uptake $\cdot$ Bone

\section{Introduction}

When carefully reviewing the orthopaedic and rheumatological literature, 20-30\% of patients after primary total knee arthroplasty (TKA) are not satisfied. A considerable number also report persistent or recurrent pain [1-5].

As the most common causes infection, aseptic loosening, instability, malposition of the TKA, arthrofibrosis and patellofemoral problems have been reported [2]. However, in many cases after TKA the cause for the patient's problems cannot be identified unambiguously [3-5]. The current routine diagnostics including conventional radiographs, CT, MRI, scintigraphy, single photon emission computed tomography (SPECT) or positron emission tomography (PET)/CT fail to 
accurately establish the correct diagnosis [2-5]. This is in part due to the fact that in many of the cases a combination of different causes is responsible for these problems.

Recently, Hirschmann et al. highlighted the clinical value of a standardized diagnostic algorithm including SPECT/CT in patients with problems after TKA [3]. They reported near perfect inter- and intra-observer reliability for their proposed standardized SPECT/CT algorithm including a localization scheme, intensity value and 3-D prosthetic component analysis $[3,6]$. With this specific algorithm the authors aim to identify typical distribution patterns and intensity thresholds of bone tracer uptake, which reflect pathologies such as mechanical loosening, instability, component malposition or patellofemoral problems [3]. Hence, they piloted the method in a consecutive series of 23 patients after TKA. It was observed that there is a distinct relationship of the position of the prosthetic components, the postoperative alignment and the pattern and intensity of bone tracer uptake in SPECT/CT [2]. They further reported that SPECT/CT significantly changed the diagnosis and subsequent treatment $[2,5]$.

By a combination of 3-D analysis of component position, mechanical and anatomical axes as well as the pattern of distribution and intensity of bone tracer uptake SPECT/CT offers a richer source of diagnostic data to the radiology, the nuclear medicine and finally the orthopaedic fraternity $[2,3,5-9]$. Hence, SPECT/CT is considered as one important diagnostic part of their routine algorithm in patients with pain, stiffness, swelling or instability after TKA.

A more profound insight into the relationship of TKA component design and position, alignment and physiological remodelling within the bone-prosthesis interface could help to establish new diagnostic algorithms and a significant improvement of specificity and sensitivity of SPECT/ CT in patients after TKA [2, 3, 5-9].

The purpose of this study was to investigate in how many patients SPECT/CT changed the diagnosis and subsequent treatment as well the sensitivity and specificity for loosening, infection, patellofemoral osteoarthritis (OA) and malposition of TKA. The secondary purpose was to identify typical patterns of bone tracer uptake distribution and intensity values in unhappy patients after TKA. The above findings were correlated with the type of TKA, the time from primary TKA surgery, type of TKA, cemented or non-cemented, and intraoperative findings at revision surgery (loose versus well-fixed TKA components).

\section{Materials and methods}

A total of 100 knees (male to female ratio $=34: 66$, mean age \pm standard deviation $70 \pm 11$ years) of 84 consecutive patients (male to female ratio $=29: 55$ ) with persistent pain after primary TKA were prospectively included. Patients who had undergone a previous TKA revision surgery were excluded. All patients underwent clinical and radiological examination including standardized radiographs (anteroposterior and lateral weightbearing, patellar skyline view) and ${ }^{99 \mathrm{~m}} \mathrm{Tc}$-hydroxymethane diphosphonate (HDP) SPECT/CT as part of a routine diagnostic algorithm (Fig. 1). Infection was ruled out clinically, by aspiration and biopsy before revision surgery. In addition, biopsies were taken intraoperatively. All infected cases were not included in this study.

Ethical approval was obtained from the local Ethics Committee. All procedures performed were in accordance with the ethical standards of the institutional and/or national research committee and with the 1964 Declaration of Helsinki and its later amendments or comparable ethical standards. Informed consent was obtained from all individual participants included in the study.

The median time from primary TKA to the date of SPECT/ CT imaging was 36 months (range 6-240 months). The patients' demographics such as age, gender, time from primary TKA, type and model of primary TKA were noted. For 53 (53\%) knees a fixed and for $47(47 \%)$ a mobile-bearing polyethylene inlay was present. A cemented TKA was found in $12(12 \%)$ femoral and $97(97 \%)$ tibial components.

The diagnosis before and after SPECT/CT imaging as well as the final treatment (surgical versus non-surgical) were recorded. Radiolucent lines and osteolysis were taken into consideration as criteria for loosening. For the intraoperative diagnosis of loosening very strict criteria were used. Only if the TKA was already toggling after standard approach including thorough synovial debridement and removal of all osteophytes it was considered to be loose.

The final diagnosis was based on microbiology, histology, clinical and radiological as well as intraoperative findings. Data were analysed to determine whether SPECT/CT had changed the diagnosis and/or subsequent treatment.

${ }^{99 \mathrm{~m}}$ Tc-HDP SPECT/CT was performed using a hybrid system (Symbia T16, Siemens, Erlangen, Germany) which consists of a pair of low-energy, high-resolution collimators and a dual-head gamma camera and an integrated $16 \times 0.75-\mathrm{mm}$ slice thickness CT. All patients received a commercial 500 $700 \mathrm{MBq}{ }^{99 \mathrm{~m}} \mathrm{Tc}-\mathrm{HDP}$ injection (Mallinckrodt, Wollerau, Switzerland). Two-plane scintigraphic images were taken in the perfusion phase (immediately after injection), the soft tissue phase (1-5 min after injection) and the delayed metabolic phase ( $2 \mathrm{~h}$ after injection). SPECT/CT was performed with a matrix size of $128 \times 128$, an angle step of 32 and a time per frame of $25 \mathrm{~s} 2 \mathrm{~h}$ after injection.

SPECT/CT images were analysed on 3-D reconstructed images for analysis of femoral and tibial TKA component position as well for measurements of bone tracer uptake (intensity and anatomical distribution pattern). The rotational (internal-external rotation), sagittal (flexion-extension, anteriorposterior slope) and coronal (varus-valgus) positions of the 


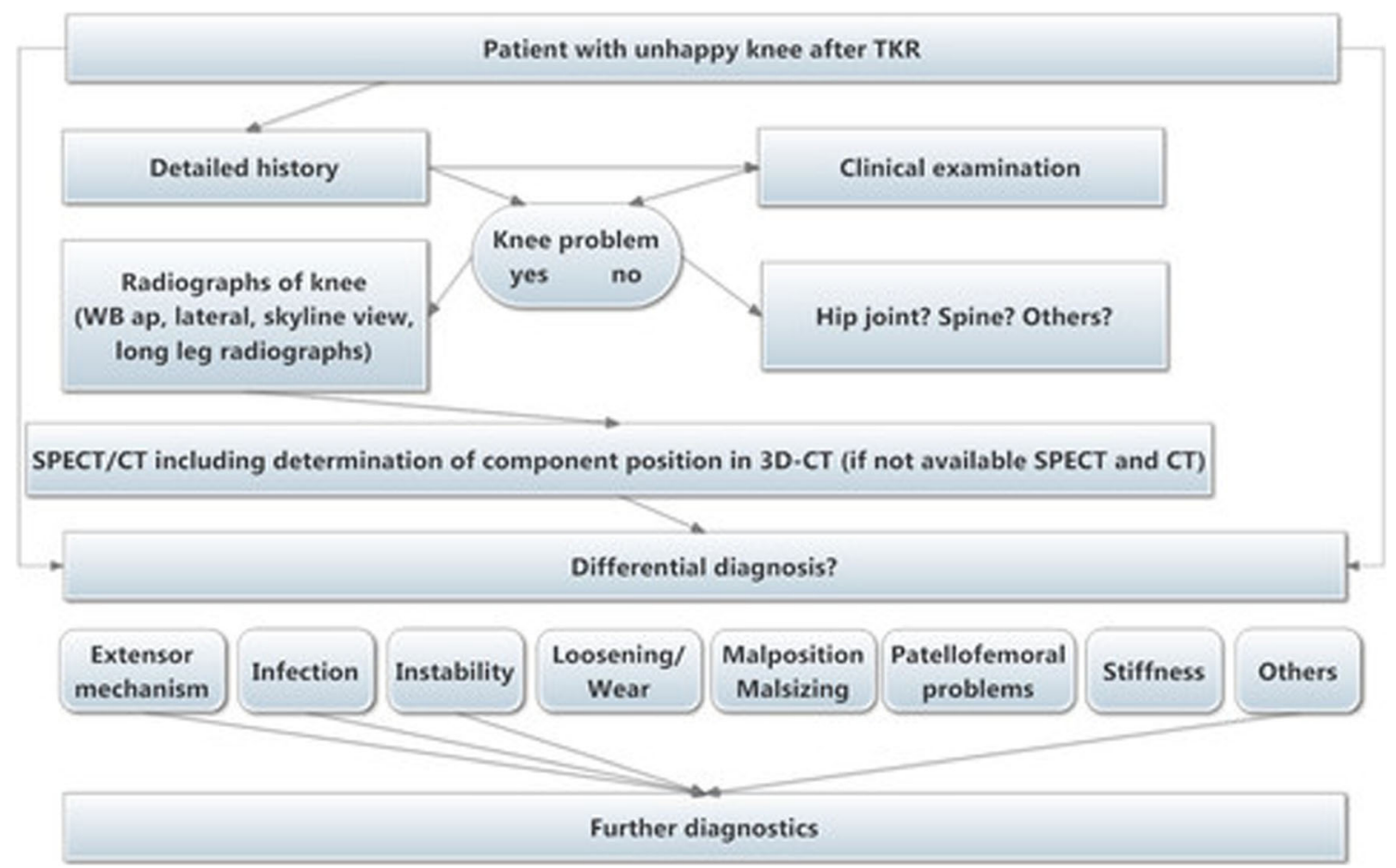

Fig. 1 Diagnostic algorithm for unhappy patients after TKA

tibial and femoral TKA components were assessed using a customized analysis software (OrthoExpert $\subseteq$, London, UK; Fig. 2). The measurement method has been previously validated and showed near perfect inter- and intra-observer reliability [3] (Fig. 3).

The anatomical areas represented by a previously validated localization scheme were volumetrically measured for bone tracer uptake intensity in 3-D. Maximum intensity values were recorded as well as ratios between the respective value in the measured area and the background tracer activities (proximal midshaft of the femur) were calculated. The inter- and intraobserver reliability (intraclass correlation coefficient, ICCs) for every area investigated was $>0.85$, which is considered to be a near perfect reliability [3].

\section{Statistical analysis}

All data were analysed by an independent professional statistician using SPSS version 17.0 (SPSS, Chicago, IL, USA). Continuous variables were described using means and standard deviations or medians and ranges. Categorical variables were tabulated with absolute and relative frequencies. Univariate analysis (chi-square test, Pearson's correlation and $t$ test for independent samples) was performed to identify any correlations between component position, tracer uptake and diagnosis. For all analysis, $p<0.05$ was considered statistically significant.

\section{Results}

SPECT/CT changed the clinical diagnosis and final treatment in $85 / 100(85 \%)$ knees. A total of 33 knees $(33 \%)$ were surgically revised (male to female ratio $=10: 23$ ), 58 knees $(58 \%)$ non-surgically treated and 9 knees $(9 \%)$ were scheduled for revision surgery.

The mean time from primary TKA for the knees being revised was $4.8 \pm 3.8$ years. In 27 knees $(82 \%)$ the femoral TKA component and in $32(97 \%)$ the tibial TKA component was cemented; 17 knees (51.5\%) had a fixed and 16 (48.5\%) a mobile-bearing polyethylene inlay. In 14/33 knees the femoral TKA component and in 12/33 knees the tibial TKA component was revised. In 20 knees a secondary patellar resurfacing was performed.

The intraoperative findings confirmed the preoperative SPECT/CT diagnosis in 32/33 knees (97\%). In one case in SPECT/CT no loosening was identified. However, intraoperatively loosening was found (Figs. 4 and 5). The bone interface was separated from the cement and TKA component by a periprosthetic membrane. Femoral $(n=7)$ and tibial loosening $(n=6)$ of the TKA was correctly diagnosed with SPECT/CT in $100 \%$ of knees. Progression of patellofemoral OA was correctly diagnosed in 19 knees (100\%).

Tibial and femoral TKA component position [varus-valgus, flexion-extension, internal rotation (IR)-external rotation (ER)] measured on 3-D CT are presented for all patients and 

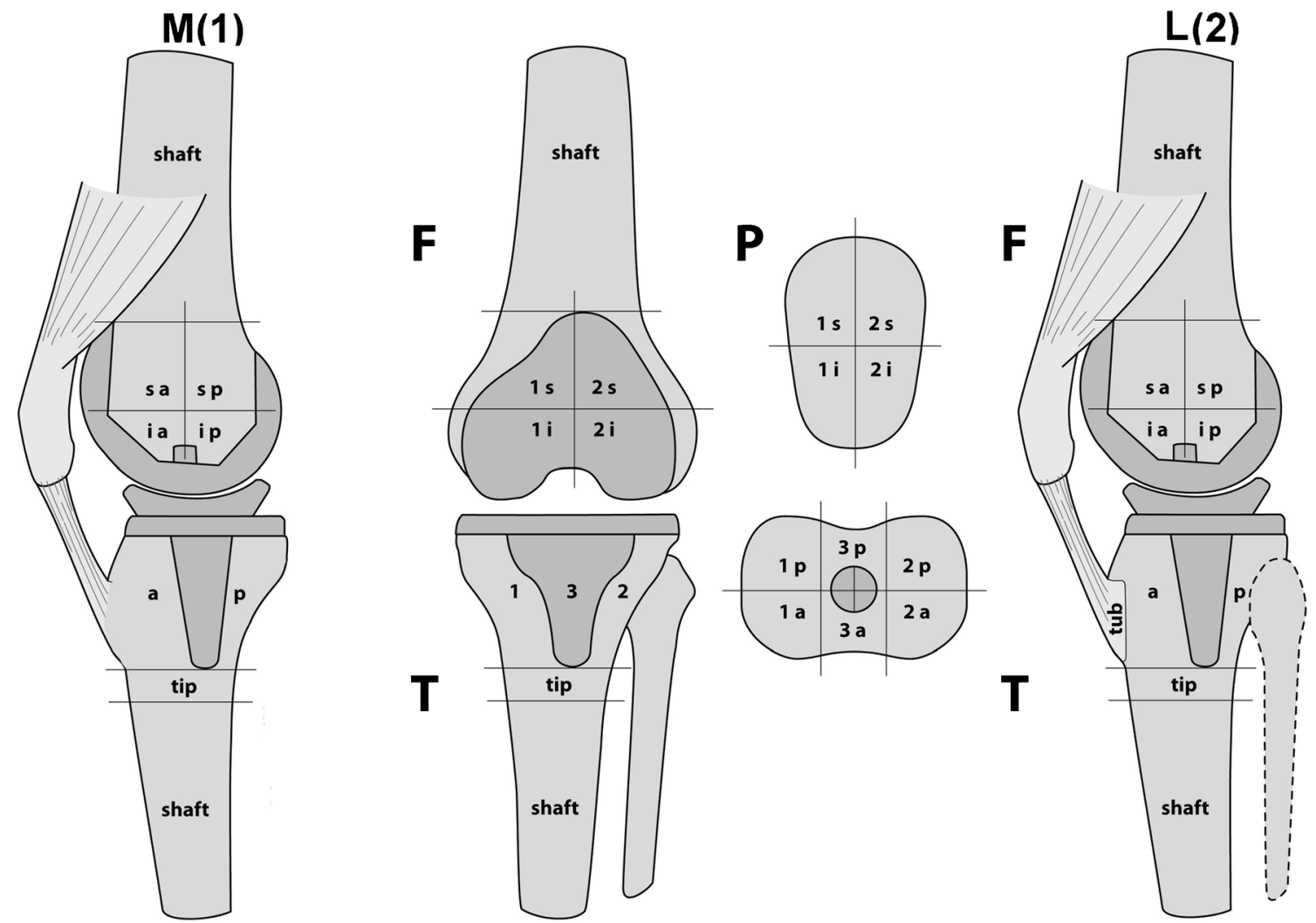

Fig. 2 The previously validated scheme for anatomical localization of bone tracer uptake (reprinted with permission)

then compared between revised and non-revised patients in Table 1.

The relationship of bone tracer uptake in each anatomical region and TKA component position is presented for the entire study group and revised TKA in Tables 2 and 3. Table 4 shows that patients with a malpositioned TKA can be identified by increased bone tracer uptake in all patellar regions.

Loose femoral TKA components significantly correlated with increased bone tracer uptake only at the lateral femoral regions (Flat sa 0.5 , Flat sp 0.57, Flat ia 0.42, Flatip 0.4; $p<0.05$ ). Loose tibial TKA components significantly correlated with increased bone tracer uptake at all tibial regions (Tmed a 0.33, Tmed p 0.37, Tlat a 0.43 , Tlat p 0.46; $p<0.05)$. In addition, there was a highly significant correlation for the regions around the tibial stem $(0.49 ; p>0.01)$. Table 5 presents diagnosis, treatment and SPECT/CT findings in all revised knees (Fig. 6). Table 6 shows typical SPECT/CT findings in relation to the pathology diagnosed.

\section{Discussion}

The most important findings of the study were:

Firstly, including SPECT/CT in a diagnostic algorithm for unhappy patients after TKA led to an improved diagnosis and treatment in $85 \%$ of patients. SPECT/CT diagnosis was confirmed in $97 \%$ intraoperatively. Loosening of tibial or femoral TKA components as well as progression of patellofemoral OA was diagnosed correctly in all patients.

These findings are in agreement with a previous study by our group. In this pilot study on 23 knees of patients with problems after TKA it was shown that SPECT/CT imaging changed the suspected diagnosis and the proposed treatment in $83 \%$ of knees [2]. Progression of patellofemoral OA, loosening of the tibial and loosening of the femoral TKA component were the leading causes of pain after TKA [2].

Due to the benefits in establishing the correct diagnosis, when performed and analysed as described here, SPECT/CT should be part of the routine diagnostic algorithm for patients with pain after TKA [5]. As bone scans or SPECT it has been shown useful for diagnosis of loosening after TKA, but was limited due to its poor specificity [10,11]. However, only qualitative analysis of bone scans and SPECT was performed.

Several years ago Klett et al. highlighted the clinical value of quantitative bone scintigraphy for the diagnosis of aseptic loosening in TKA [12]. They retrospectively investigated 31 tibial components of cemented total knee prostheses using quantitative bone scintigraphy and found a sensitivity of 0.9 , a specificity of 1 , a negative predictive value of 0.85 , a positive predictive value of 1 and an accuracy of 0.94 , respectively [12]. The authors concluded that quantitative bone scintigraphy appears to be a reliable diagnostic tool for aseptic 


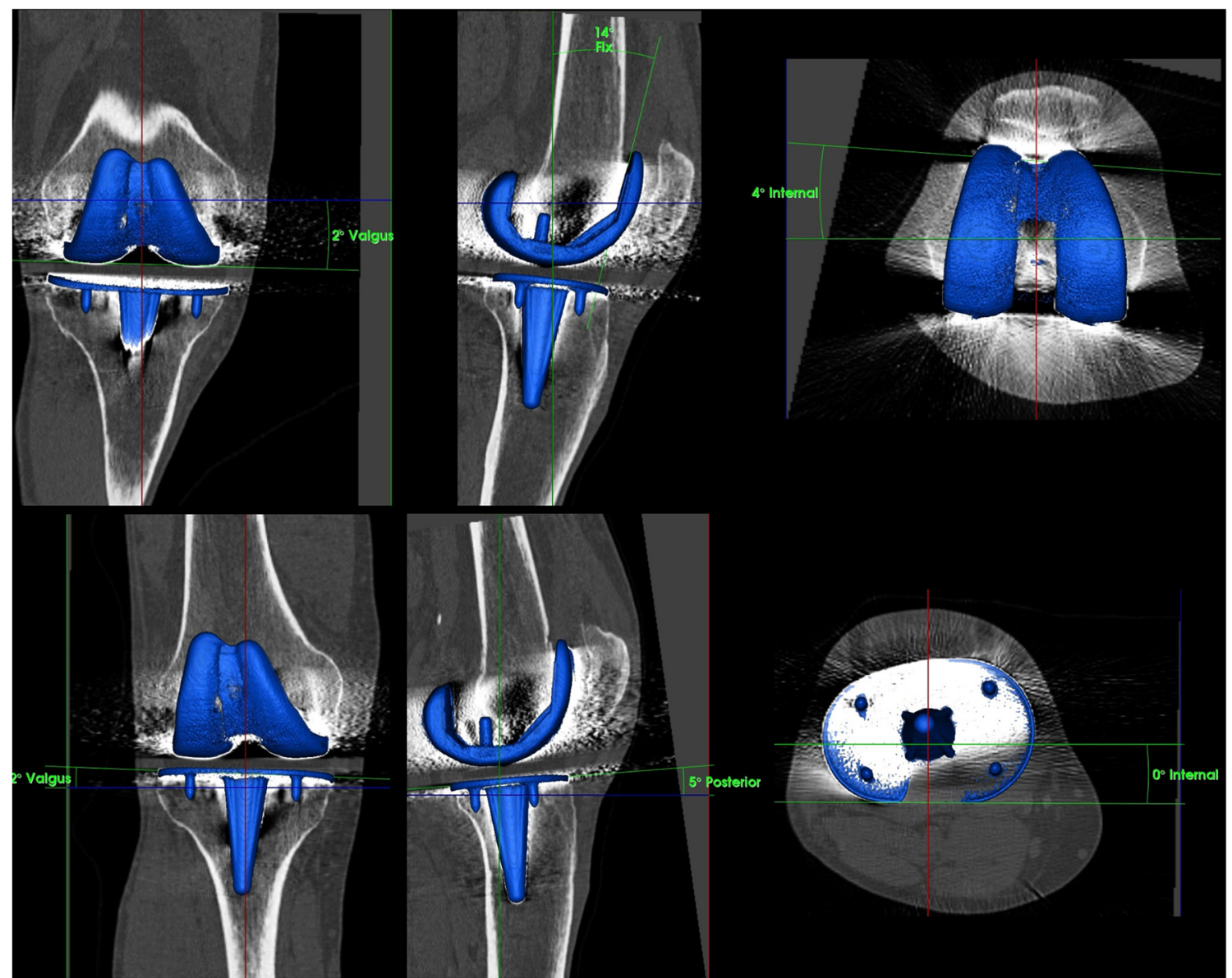

Fig. 3 Measurement of femoral and tibial TKA component positions (varus-valgus, flexion-extension, internal rotation-external rotation) in 3-D reconstructed CT images using a customized software [3]

loosening [12]. However, Sacchetti et al. reported a low reproducibility for the quantitative measurements using region of interest (ROI) analysis [13].

Many authors used bone densitometry for assessment of bone density around TKA [14-17]. In contrast to bone densitometry, in which only the density of bone is detected, SPECT/CT offers a window into the process of bone remodelling. In addition, it has a better ability to localize areas of increased or decreased bone tracer uptake. Localization of bone density around TKA is rather inaccurate and broad. The bone tracer is directed towards bone-forming minerals, which are produced by active osteoblasts [18].

In theory the process of aseptic loosening leads to micromotion of the TKA components. Aiming for stabilization
Fig. 4 Patient with loosening of tibial TKA component, which is identified by the increased bone tracer uptake around the tibial peg and the tibial plateau

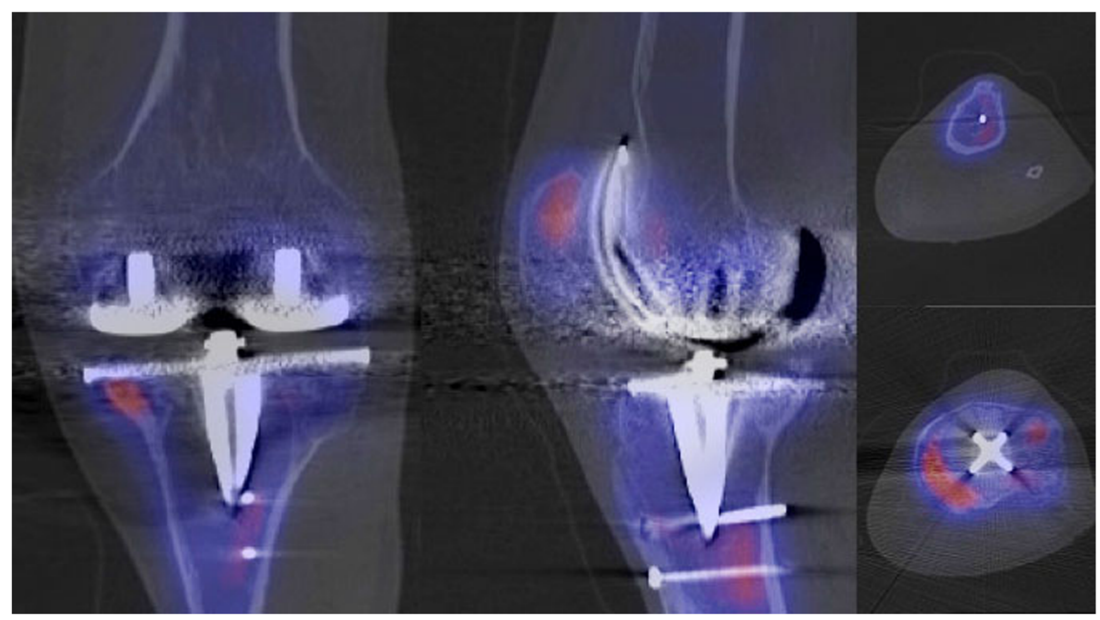


Fig. 5 Loosening of a patellar component after TKA with increased bone tracer uptake at the entire patellar bone and clear radiolucent lines (arrow)

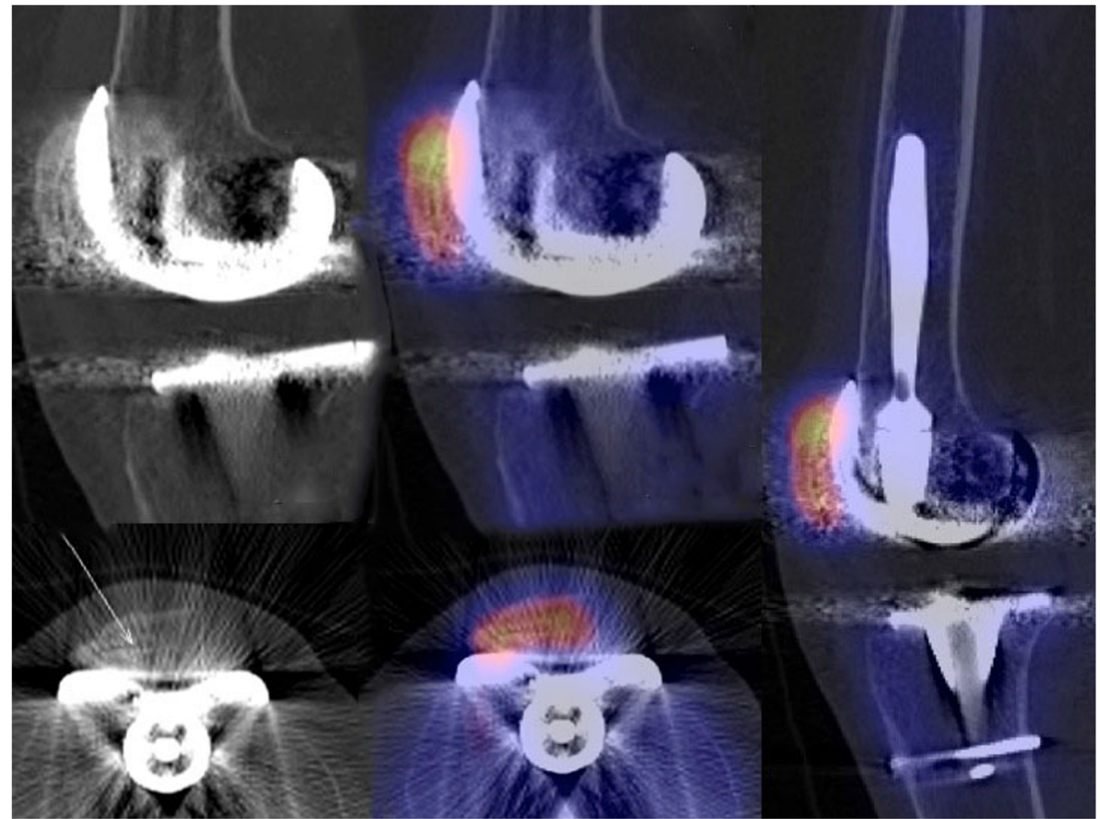

of the TKA components osteoblastic activity is increased resulting in increased secretion of calcified bone matrix, which can then be identified in bone scans [11]. However, in a study by $\mathrm{Li}$ and Nilsson no correlation between micromotion of the tibial TKA component and bone density values was found [19]. Besides aseptic loosening of TKA components it was shown that SPECT/CT is also helpful for diagnosis of patellofemoral problems such as progression of patellofemoral disease, patellar maltracking, overstressing of the patella due to patella baja or femoral component malposition [2, 20, 21].

Ahmad et al. previously suggested using bone scans as a screening tool for patellofemoral problems in patients with pain after TKA [22]. The authors found that a hot patella was significantly correlated with anterior knee pain [22]. A normal bone scan following TKA surgery is reassuring and suggests that a patellofemoral problem is unlikely [22].

In contrast to this previous study, in which bone scans were analysed, SPECT/CT offers an improved localization of bone tracer uptake. With regard to the patellar bone four quadrants were analysed, which is considered to increase its specificity. Patellar maltracking or the influence of femoral TKA malposition, in particular flexion and internal rotation, can be assessed.

Secondly, highly accurate measurement of TKA component position (varus-valgus, flexion-extension, IR-ER) on 3$D$ reconstructed $\mathrm{CT}$ images contributed to establishment of the correct diagnosis. In contrast to the current gold standard, determination of the femoral TKA rotation on axial CT slices, which showed a high inter- and intra-observer variability, in this study TKA component position was determined on 3-D reconstructed $\mathrm{CT}$ after alignment to standardized frames of reference, which is inherent in the SPECT/CT data [23]. In previous studies this measurement method was shown to be highly accurate $[2,3,23,24]$.

Analysis of bone tracer uptake patterns in these patients could only be understood by including determination of TKA

Table 1 Tibial and femoral component position (varus-valgus, flexion-extension, IR-ER) measured on 3-D CT using customized software comparing all knees with the subgroup of knees being revised

\begin{tabular}{|c|c|c|c|c|c|c|}
\hline & \multicolumn{3}{|l|}{ Femoral } & \multicolumn{3}{|l|}{ Tibial } \\
\hline & $\begin{array}{l}\text { Varus }(+) \text {, valgus } \\
(-), \text { mean } \pm \mathrm{SD} \text {, } \\
\text { range }\end{array}$ & $\begin{array}{l}\text { Flexion }(+), \text { extension } \\
(-) \text {, mean } \pm \mathrm{SD} \text {, median, } \\
\text { range }\end{array}$ & $\begin{array}{l}\mathrm{ER}(+), \mathrm{IR}(-), \\
\text { mean } \pm \mathrm{SD}, \text { range }\end{array}$ & $\begin{array}{l}\text { Varus }(+) \text {, valgus } \\
(-), \text { mean } \pm \mathrm{SD} \text {, } \\
\text { range }\end{array}$ & $\begin{array}{l}\text { Post. slope }(+) \text {, ant. } \\
\text { slope }(-) \text {, mean } \pm \mathrm{SD} \text {, } \\
\text { range }\end{array}$ & $\begin{array}{l}\mathrm{ER}(+), \mathrm{IR}(-), \\
\text { mean } \pm \mathrm{SD} \text {, range }\end{array}$ \\
\hline \multirow[t]{3}{*}{ All knees, $n=100$} & $6.2+/-3.6$ & $1.7+/-5.1$ & $1.1+/-4.1$ & $3.2+/-2.6$ & $7.1+/-3.6$ & $-4.7+/-8.0$ \\
\hline & 6.2 & 1.7 & 1.8 & 3.3 & 7.1 & -4.5 \\
\hline & -0.8 to 16.5 & -11.5 to 15.2 & -11.7 to 11.2 & -10.4 to 9.1 & -2.2 to 18.7 & -26.7 to 19.2 \\
\hline \multirow[t]{3}{*}{ Revised knees, $n=33$} & $6.4 \pm 4.2^{\circ}$ & $1.7 \pm 5.8^{\circ}$ & $1.3 \pm 4.5^{\circ}$ & $2.7 \pm 2.3^{\circ}$ & $7.0 \pm 4.0^{\circ}$ & $-1.8 \pm 9.1^{\circ}$ \\
\hline & $6.1^{\circ}$ & $1.8^{\circ}$ & $1.8^{\circ}$ & $3.1^{\circ}$ & $7.1^{\circ}$ & $0.4^{\circ}$ \\
\hline & -0.2 to $16.2^{\circ}$ & -11.5 to $15.2^{\circ}$ & -11.3 to $11.2^{\circ}$ & -1.1 to $6.8^{\circ}$ & -2.2 to $17.5^{\circ}$ & -26.7 to $19.2^{\circ}$ \\
\hline
\end{tabular}


Table 2 Relationship of bone tracer uptake and TKA component position in the entire series of 100 knees (Pearson's $r$ )

\begin{tabular}{lcccccc}
\hline & $\begin{array}{l}\text { F flexion/ } \\
\text { extension }\end{array}$ & $\begin{array}{l}\text { F external rotation/ } \\
\text { internal rotation }\end{array}$ & $\begin{array}{l}\text { F varus/ } \\
\text { valgus }\end{array}$ & T slope & $\begin{array}{l}\text { T external rotation/ } \\
\text { internal rotation }\end{array}$ & $\begin{array}{c}\text { T varus/ } \\
\text { valgus }\end{array}$ \\
\hline Fmed sa & 0.02 & 0.02 & -0.02 & 0.19 & -0.05 & 0.18 \\
Fmed sp & 0.00 & -0.02 & -0.04 & 0.18 & 0.04 & 0.11 \\
Fmed ia & 0.03 & 0.03 & -0.10 & -0.04 & 0.05 & -0.03 \\
Fmed ip & 0.03 & 0.03 & -0.14 & 0.02 & 0.05 & 0 \\
Flat sa & -0.03 & -0.04 & 0.02 & 0.06 & 0.02 & 0.14 \\
Flat sp & 0.10 & 0.02 & -0.08 & 0.06 & -0.03 & 0.04 \\
Flat ia & 0.07 & 0.02 & -0.06 & -0.07 & 0.15 & -0.07 \\
Flat ip & 0.10 & 0.01 & -0.08 & -0.10 & 0.07 & 0 \\
Tmed a & 0.05 & 0.04 & 0.10 & 0.08 & 0.01 & 0.11 \\
Tmed p & 0.00 & 0.04 & 0.07 & 0.07 & -0.06 & 0.11 \\
Tlat a & 0.07 & 0.11 & 0.13 & 0.02 & 0.04 & -0.02 \\
Tlat p & 0.08 & 0.13 & 0.19 & 0.11 & -0.04 & -0.05 \\
T peg & 0.06 & 0.06 & 0.08 & -0.02 & -0.01 & -0.08 \\
T tip & $0.28 * *$ & -0.09 & -0.09 & 0.13 & -0.12 & 0.05 \\
Pmed s & 0.04 & -0.11 & -0.12 & 0.02 & 0.06 & -0.01 \\
Pmed i & 0.06 & -0.07 & -0.04 & 0.03 & 0.05 & -0.01 \\
Plat s & 0.05 & -0.07 & -0.10 & -0.08 & 0.07 & 0.08 \\
Plat i & 0.00 & -0.12 & -0.05 & -0.09 & 0.09 & -0.1 \\
\hline
\end{tabular}

$F$ femur, $T$ tibia, $P$ patella, med medial, lat lateral, peg around tibial peg, tip tip of peg, $s$ superior, $i$ inferior, $a$ anterior, $p$ posterior

$* * p<0.01$

\begin{tabular}{lcllccc}
\hline & $\begin{array}{l}\text { F flexion/ } \\
\text { extension }\end{array}$ & $\begin{array}{l}\text { F external rotation/ } \\
\text { internal rotation }\end{array}$ & $\begin{array}{l}\text { F varus/ } \\
\text { valgus }\end{array}$ & T slope & $\begin{array}{l}\text { T external rotation/ } \\
\text { internal rotation }\end{array}$ & $\begin{array}{l}\text { T varus/ } \\
\text { valgus }\end{array}$ \\
\hline Fmed sa & 0.17 & $-0-07$ & 0.01 & $0.38^{*}$ & -0.07 & 0.10 \\
Fmed sp & 0.12 & -0.09 & -0.10 & $0.35^{*}$ & 0.08 & 0.10 \\
Fmed ia & 0.16 & $-0-07$ & -0.12 & 0.20 & 0.07 & -0.04 \\
Fmed ip & 0.05 & -0.03 & -0.18 & 0.16 & 0.14 & -0.10 \\
Flat sa & -0.05 & -0.14 & -0.01 & 0.05 & 0.15 & 0.09 \\
Flat sp & 0.25 & -0.30 & -0.15 & -0.06 & 0.19 & -0.03 \\
Flat ia & 0.16 & -0.11 & -0.11 & 0.02 & 0.25 & -0.13 \\
Flat ip & 0.33 & -0.24 & -0.15 & -0.16 & 0.26 & -0.10 \\
Tmed a & 0.23 & -0.05 & 0.12 & $0.41 *$ & -0.04 & -0.02 \\
Tmed p & 0.11 & 0.02 & 0.11 & 0.30 & 0.04 & -0.01 \\
Tlat a & 0.29 & 0.09 & 0.29 & 0.24 & -0.08 & 0.14 \\
Tlat p & 0.23 & 0.13 & 0.34 & 0.26 & -0.10 & -0.24 \\
T peg & 0.24 & 0.07 & 0.23 & 0.33 & -0.03 & -0.14 \\
T tip & 0.30 & -0.27 & -0.07 & 0.33 & -0.18 & 0.09 \\
Pmed s & 0.05 & -0.25 & -0.29 & 0.09 & -0.01 & -0.16 \\
Pmed i & 0.11 & -0.19 & -0.25 & 0.03 & 0.03 & -0.08 \\
Plat s & 0.14 & -0.23 & -0.22 & 0.05 & -0.02 & -0.19 \\
Plat i & 0.10 & $-0,28$ & -0.18 & 0.01 & 0.03 & 0.02 \\
\hline
\end{tabular}

$F$ femur, $T$ tibia, $P$ patella, med medial, lat lateral, peg around tibial peg, tip tip of peg, $s$ superior, $i$ inferior, $a$ anterior, $p$ posterior

$*_{p}<0.05$
Table 3 Relationship of bone tracer uptake and TKA component position in the patients revised $(n=33)$

(Pearson's $r$ ) 
Table $4{ }^{99 \mathrm{~m}} \mathrm{Tc}-\mathrm{HDP}$ bone tracer uptake in each anatomical region correlated with correctly positioned TKA ( $t$ test for independent samples)

\begin{tabular}{llll}
\hline Revision (incl. planned) & $\begin{array}{l}\text { No } \\
\text { Mean } \pm \text { SD }\end{array}$ & $\begin{array}{l}\text { Yes } \\
\text { Mean } \pm \text { SD }\end{array}$ & $\begin{array}{l}\text { Diff. } \\
p\end{array}$ \\
\hline Fmed sa RFS & $2.55( \pm 1.9)$ & $2.52( \pm 1.33)$ & 0.964 \\
Fmed sp RFS & $3.05( \pm 2.71)$ & $3.03( \pm 1.61)$ & 0.374 \\
Fmed ia RFS & $2.32( \pm 1.38)$ & $2.56( \pm 1.24)$ & 0.534 \\
Fmed ip RFS & $2.74( \pm 1.55)$ & $2.94( \pm 1.71)$ & 0.119 \\
Flat sa RFS & $2.8( \pm 2.02)$ & $3.48( \pm 2.29)$ & 0.670 \\
Flat sp RFS & $3.32( \pm 2.44)$ & $3.51( \pm 1.7)$ & 0.014 \\
Flat ia RFS & $2.34( \pm 1.2)$ & $3.12( \pm 1.9)$ & 0.236 \\
Flat ip RFS & $3.05( \pm 1.54)$ & $3.42( \pm 1.55)$ & 0.754 \\
Tmed a RFS & $2.92( \pm 1.7)$ & $3.03( \pm 1.53)$ & 0.866 \\
Tmed p RFS & $3.42( \pm 2.16)$ & $3.35( \pm 1.77)$ & 0.131 \\
Tlat a RFS & $2.65( \pm 1.35)$ & $3.1( \pm 1.62)$ & 0.406 \\
Tlat p RFS & $2.97( \pm 1.49)$ & $3.24( \pm 1.77)$ & 0.387 \\
T stem RFS & $2.63( \pm 1.41)$ & $2.88( \pm 1.44)$ & 0.293 \\
T tip RFS & $1.49( \pm 0.6)$ & $1.63( \pm 0.75)$ & 1.000 \\
T shaft RFS & $1.08( \pm 0.39)$ & $1.08( \pm 0.37)$ & 0.007 \\
Pmed s RFS & $2.93( \pm 1.6)$ & $4.01( \pm 2.32)$ & 0.002 \\
Pmed i RFS & $2.56( \pm 1.35)$ & $3.78( \pm 2.44)$ & 0.007 \\
Plat s RFS & $3.01( \pm 1.68)$ & $4.1( \pm 2.24)$ & 0.001 \\
Plat i RFS & $2.64( \pm 1.46)$ & $4.02( \pm 2.4)$ & 0.002 \\
\hline
\end{tabular}

$F$ femur, $T$ tibia, $P$ patella, med medial, lat lateral, peg around tibial peg, tip tip of peg, $s$ superior, $i$ inferior, $a$ anterior, $p$ posterior, RFS ratio to femur shaft region

component position. Increased bone tracer uptake in SPECT/CT represents bone remodelling, which is present in overloading situations of specific areas. In these cases the equilibrium of bone resorption and formation is shifted towards bone formation.

Position of the tibial TKA component in varus is known to cause early loosening or varus collapse of the bone [25-27]. If the tibial TKA component is placed in varus, increased bone tracer uptake in the medial tibial regions is found. The effect of positioning the tibial TKA component in varus or valgus has been investigated previously by Werner et al. showing increased contact stresses and loading in patients with coronal malpositioned tibial TKA components [28]. This finding explains the remodelling of the bone as a reaction to higher loads in the medial tibial plateau. In a previous study a clear relationship of coronal alignment (varus-valgus) and bone tracer uptake in SPECT/CT was identified [29].

Besides coronal alignment rotational malalignment is considered to be associated with poor clinical outcome after TKA $[31,30]$. Internal femoral rotation leads to patellar maltracking such as edge loading of the lateral patellar facet $[31,30]$. Other symptoms might be pain, stiffness or instability.

Generally tibial malrotation is increased internal rotation. However, also increased external rotation can occur. Internal rotation of the tibial TKA component leads to increased medial collateral ligament (MCL) forces and might result in pain at the medial joint compartment [32]. The increase in lateral collateral ligament (LCL) forces is only half of the MCL forces [32]. In addition, the contact area was decreased and contact stresses were increased in internally rotated tibial TKA components [32]. A similar effect was investigated for external rotation of tibial TKA.

In another study Kessler et al. have shown that tibiofemoral TKA component malrotation, whether internal or external rotation, causes an increase in tibial torque and compressive strains which might be an important factor for aseptic loosening of the tibial TKA component [33]. With SPECT/CT one could be able to identify not only optimal alignment for each patient, but also investigate which alignment leads to what bone remodelling represented by bone tracer uptake and finally to a knee joint in homeostasis.

Thirdly, typical bone tracer uptake patterns were identified for femoral and tibial loosening. This is the first time that these have been reported, which should be used to build guidelines for reporting of SPECT/CT images in patients after TKA. It was found that increased bone tracer uptake only at the lateral femoral regions was indicative of loosening of the femoral TKA component. This was in contrast to tibial loosening, in which increased bone tracer uptake was seen in all tibial regions and around the tibial stem.

Increased bone tracer uptake at the lateral femur might be explained by the fact that lateral femoral regions in TKA are subject to more loading due to physiologically more rotational laxity. Petersen et al. found a $22 \%$ increase proximal to the fixation pegs and a $36 \%$ decrease of bone density behind the anterior femoral flange at 24 months after TKA [34, 35]. Similar findings were reported by others $[14,15,36]$. Another study by Minoda et al. showed that a cemented mobilebearing TKA has less bone loss in the distal femur than a cemented fixed-bearing TKA [17].

At the tibia increased bone tracer uptake around the tibial stems can be interpreted as a sign of tibial loosening, as it is considered to represent micromotion, in particular of the tibial stem [11]. After TKA significant bone loss in the proximal tibia was found by several authors [14, 15, 19, 37]. This bone loss was particularly high within the first 6 months and then decreased until 2 years after TKA [14, 15, 19, 37]. Windisch et al. highlighted that the highest bone loss after uncemented TKA was found within the first 3 months in the proximal medial tibia [16].

It is known from previous work that the design of the tibial stem influences bone density after TKA [38]. Bone densities of the proximal tibia were compared between two cemented tibial peg designs, one with four 0.5 -cm-long short cemented fixation pegs and the other one with a 4-cm cemented fixation peg [38]. It was found that in the longer stemmed group the metaphyseal bone density was significantly reduced, which is due to stress shielding and consequent proximal 


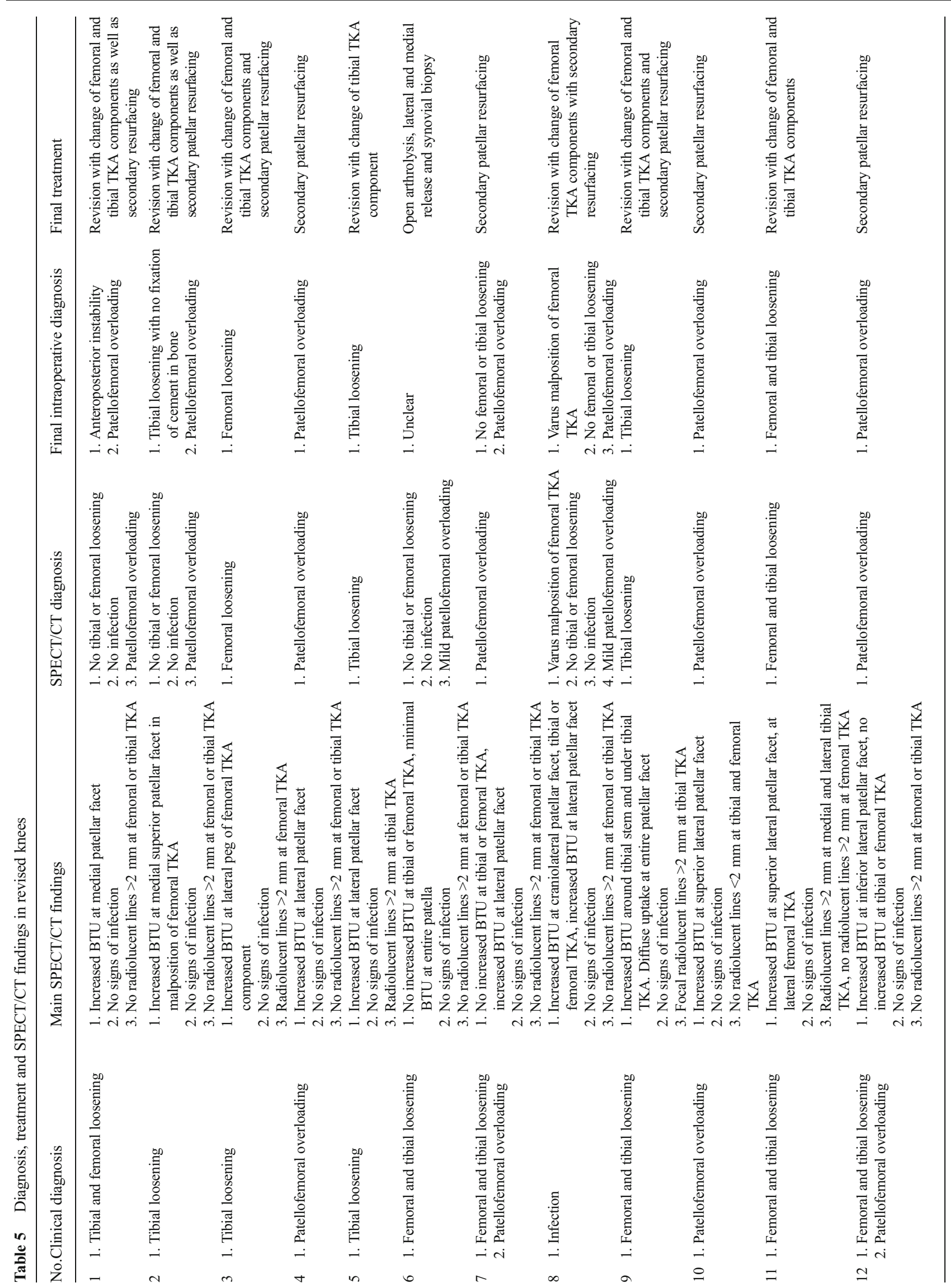




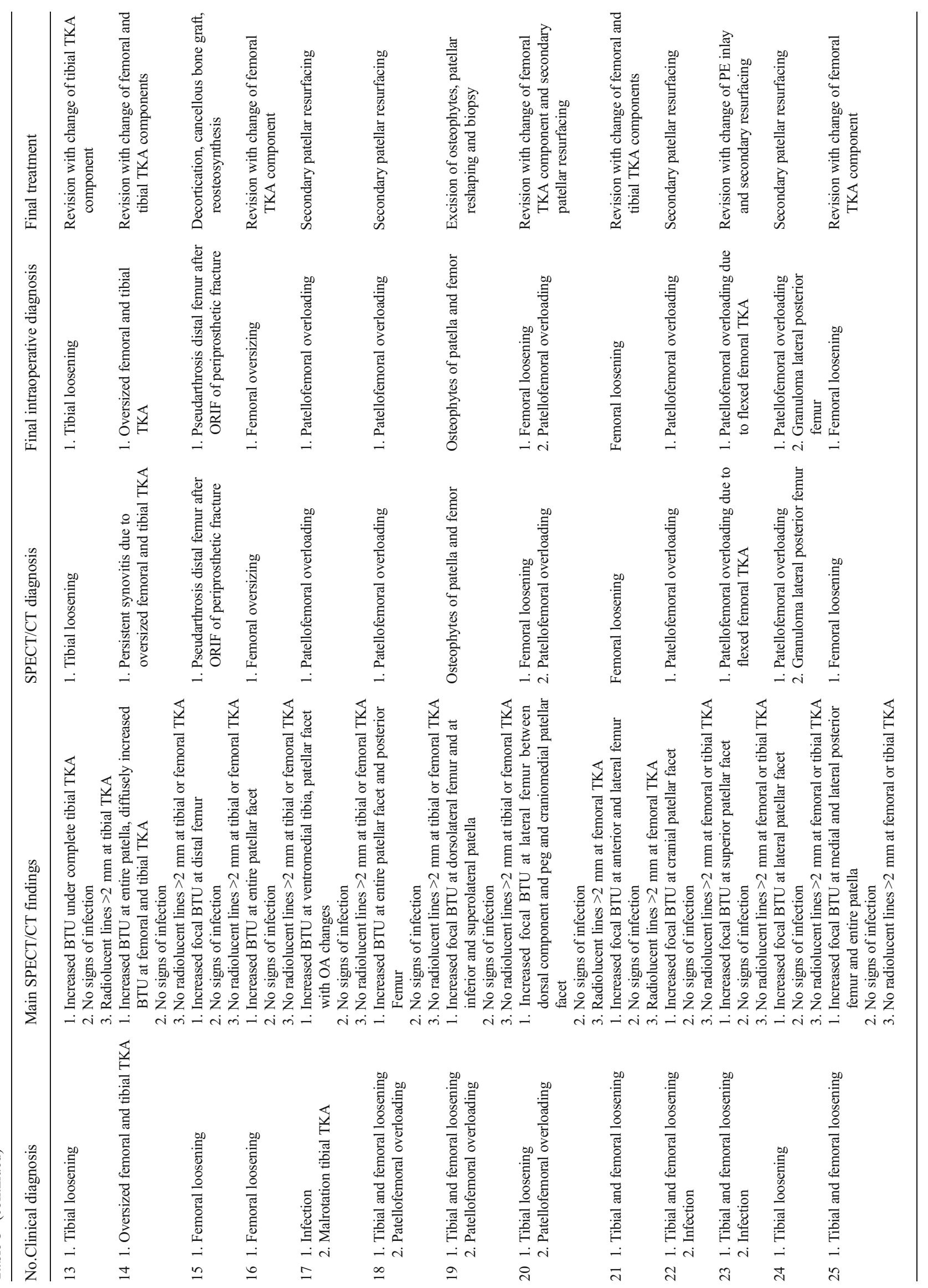




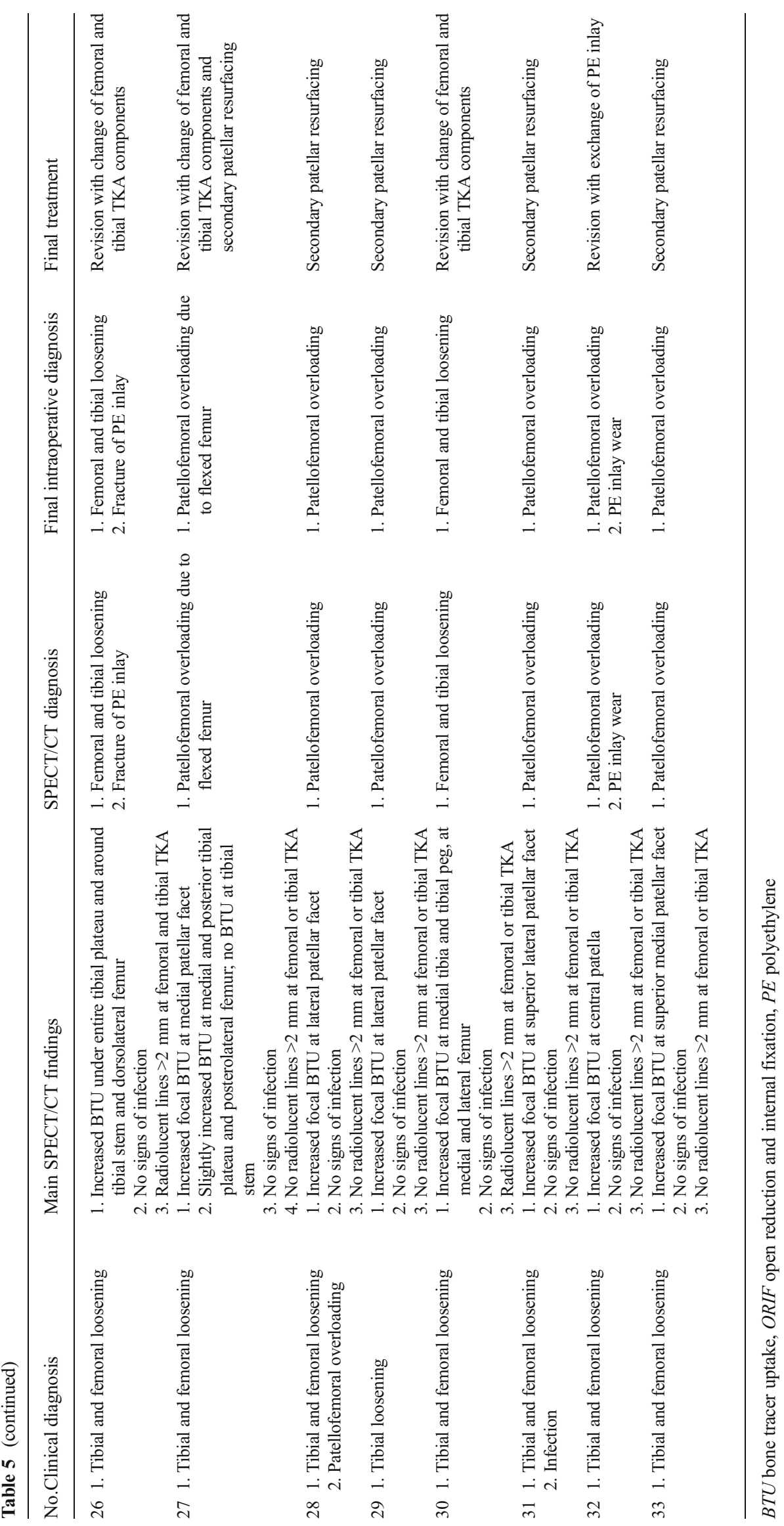




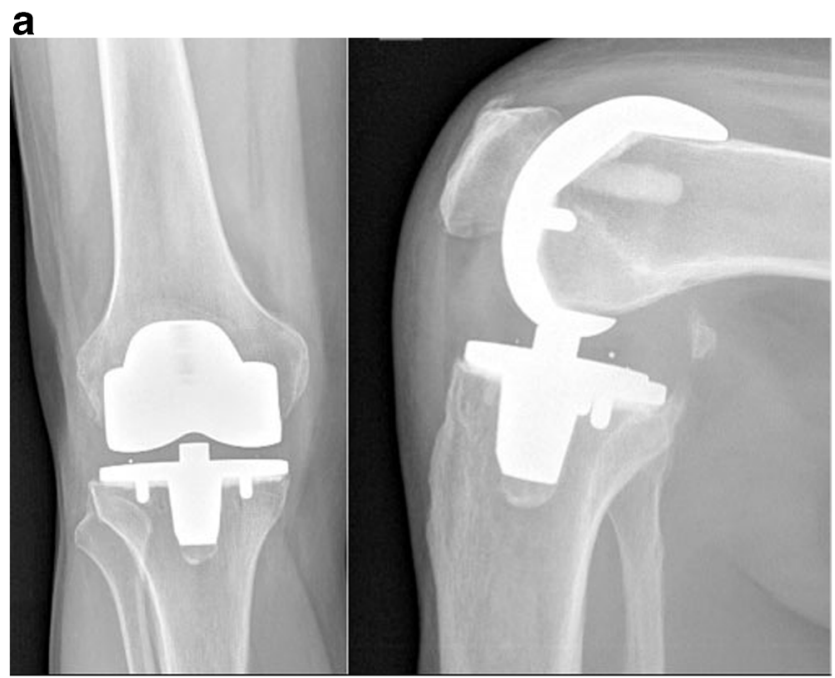

b

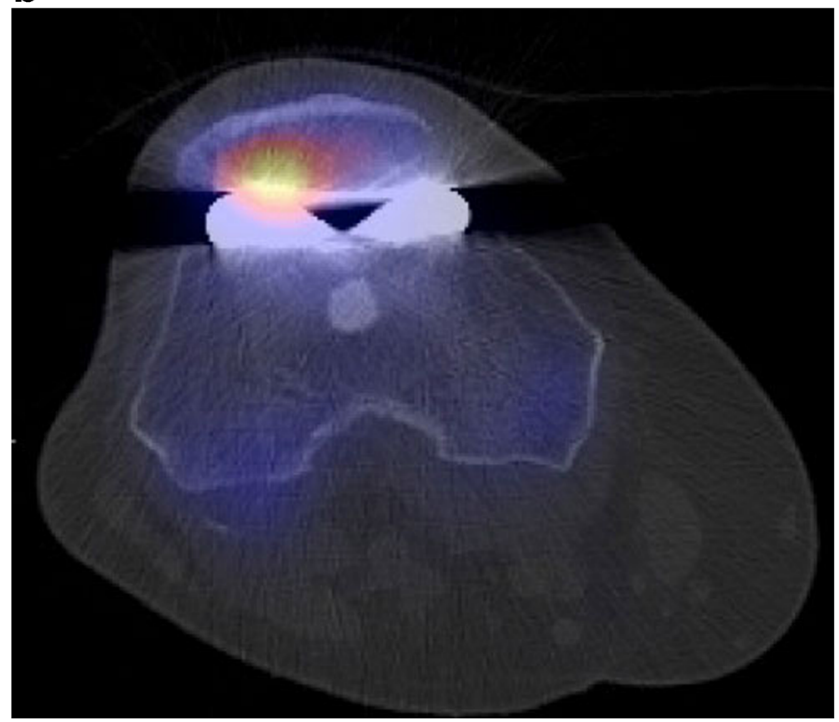

Fig. 6 Patient with patellofemoral overloading due to insufficient posterior cruciate ligament (PCL) after TKA. a Anteroposterior and lateral radiographs showing a posteriorly translated tibia indicating an insufficiency of the PCL. b Transverse SPECT/CT image showing the overloading of the patella due to PCL insufficiency in a posterior cruciate-retaining TKA bone resorption [38]. It has also been postulated that the design of the tibial short stem (cruciform versus cylindrical) influences bone remodelling after TKA [39]. It was found that cylindrically shaped short stems lead to an asymmetrical tibial decrease in bone density after TKA [39]. A slight decrease laterally, an insignificant decrease centrally and a large decrease medially was seen [39]. The authors concluded that this could lead to medial subsidence of the tibial TKA component [39]. A major limitation of this study was that TKA position was not assessed.

The type of bearing (mobile versus fixed) might also influence cortical tibial bone strains after TKA, in particular in malrotated tibial TKA components [40]. From all these studies including the present one it is clear that a well-fixed and perfectly positioned and aligned tibial TKA component shows no significant bone tracer uptake at the medial and lateral tibial plateau.

In SPECT/CT the bone tracer uptake at the patella was significantly higher in all areas and all patients with a malpositioned TKA. Due to the small sample size, it was however not possible to assess which malposition influences bone tracer uptake in which way. Further investigations are needed to shed more light on this challenging issue. It is our clinical experience that in internally rotated femoral TKA components edge loading on the lateral patellar rim can occur. In flexed femoral TKA components an increased bone tracer uptake at the proximal patellar is frequently seen, which is due to overstuffing of the patellofemoral joint.

From a study by Fitzpatrick et al. it is known that the patellar bone undergoes increased loading after TKA [41]. It was surprisingly found that in contrast to the non-resurfaced knee, in which the loads were equally distributed between medial and lateral patellar bone, in the resurfaced knee significantly larger volumes of highly strained bone were found in the medial patella [41]. However, there is only scarce evidence in terms of loading of the patella before and after TKA.

Table 6 Typical SPECT/CT appearance for loosening and patellofemoral overloading and femoral malrotation

\begin{tabular}{|c|c|c|c|}
\hline Pathology & $\begin{array}{l}\text { SPECT/CT } \\
\text { BTU findings }\end{array}$ & $\begin{array}{l}\text { SPECT/CT } \\
\text { CT findings }\end{array}$ & Pitfalls \\
\hline Femoral loosening & $\begin{array}{l}\text { Increased BTU at lateral and/or } \\
\text { medial posterior femur }\end{array}$ & $\begin{array}{l}\text { Radiolucent lines around pegs or } \\
\text { around entire femoral interface }\end{array}$ & - \\
\hline Tibial loosening & $\begin{array}{l}\text { Increased BTU below tibial TKA, } \\
\text { around tibial pegs and stem }\end{array}$ & $\begin{array}{l}\text { Radiolucent lines around pegs, stem } \\
\text { or around entire tibial interface }\end{array}$ & $\begin{array}{l}\text { In TKA with posterior slope increased BTU at } \\
\text { posterior tibia represents bone remodelling }\end{array}$ \\
\hline Patellofemoral overloading & $\begin{array}{l}\text { Increased BTU at medial or lateral or } \\
\text { superior or inferior patellar facet }\end{array}$ & $\begin{array}{l}\text { Sclerotic or cystic changes of patellar } \\
\text { facet }\end{array}$ & $\begin{array}{l}\text { Increased BTU at entire patellar facet } \\
\text { represents more likely bone remodelling }\end{array}$ \\
\hline Femoral internal malrotation & $\begin{array}{l}\text { Increased BTU at lateral patellar } \\
\text { facet }\end{array}$ & $\begin{array}{l}\text { Sclerotic or cystic changes of patellar } \\
\text { facet }\end{array}$ & - \\
\hline Femoral external malrotation & $\begin{array}{l}\text { Increased BTU at medial patellar } \\
\text { facet }\end{array}$ & $\begin{array}{l}\text { Sclerotic or cystic changes of patellar } \\
\text { facet }\end{array}$ & - \\
\hline
\end{tabular}

$B T U$ bone tracer uptake 
In future it might be possible to establish diagnostically relevant and pathologically specific bone tracer uptake thresholds, which are then indicative of loosening, patellofemoral overloading in unresurfaced patellae or other pathologies at an early stage of the disease process. For this purpose larger samples of patients after TKA need to be investigated.

\section{Limitations}

This study bears the following limitations. Including 100 knees of painful patients after TKA represents the largest study investigating the use of SPECT/CT in this challenging group of patients. However, this is still rather small when investigating the correlation of bone tracer uptake and TKA component position as well as specific pathologies. Hence, these results might become more clinically relevant when investigating a larger sample.

In addition, this study sample represents patients who are not satisfied after TKA complaining about pain, instability, stiffness or swelling. A natural history group as a control group is currently under investigation and will give additional information on the relationship of specific pathologies such as loosening of TKA components as well as patellofemoral problems and bone tracer uptake.

A variety of different TKA implant brands and designs have been studied, which might have some influence on bone tracer uptake. However, only primary TKA designs such as cruciate-retaining and posterior cruciate ligament-stabilizing TKA were included here.

Optimal reporting of SPECT/CT in patients after TKA requires a very intensive collaboration of the referring orthopaedic surgeon and the nuclear medicine radiologist. In current clinical practice very often the referring orthopaedic surgeon only gives minimal clinical or surgical background information. However, this is of utmost importance for interpretation of SPECT/CT images. Only with good communication between the referring surgeon and nuclear medicine physician can satisfactory reporting quality be achieved.

\section{Compliance with ethical standards}

Funding This study was funded by a research grant from Deutsche Arthrose-Hilfe e.V., Frankfurt, Germany.

\section{Conflicts of interest None.}

Research involving human participants and/or animals All procedures performed in studies involving human participants were in accordance with the ethical standards of the institutional and/or national research committee and with the 1964 Declaration of Helsinki and its later amendments or comparable ethical standards.

Consent to participate Informed consent was obtained from all individual participants included in the study.

\section{References}

1. Mannion AF, Kämpfen S, Munzinger U, Kramers-de Quervain I. The role of patient expectations in predicting outcome after total knee arthroplasty. Arthritis Res Ther 2009;11(5):R139. doi:10. 1186/ar2811.

2. Hirschmann MT, Konala P, Iranpour F, Kerner A, Rasch H, Friederich NF. Clinical value of SPECT/CT for evaluation of patients with painful knees after total knee arthroplasty-a new dimension of diagnostics? BMC Musculoskelet Disord 2011;12:36. doi: 10.1186/1471-2474-12-36.

3. Rasch H, Falkowski AL, Forrer F, Henckel J, Hirschmann MT. 4DSPECT/CT in orthopaedics: a new method of combined quantitative volumetric 3D analysis of SPECT/CT tracer uptake and component position measurements in patients after total knee arthroplasty. Skeletal Radiol 2013;42(9):1215-23. doi:10.1007/ s00256-013-1643-2.

4. Hirschmann MT, Testa E, Amsler F, Friederich NF. The unhappy total knee arthroplasty (TKA) patient: higher WOMAC and lower KSS in depressed patients prior and after TKA. Knee Surg Sports Traumatol Arthrosc 2013;21(10):2405-11. doi:10.1007/s00167013-2409-z.

5. Hirschmann MT, Henckel J, Rasch H. SPECT/CT in patients with painful knee arthroplasty-what is the evidence? Skeletal Radiol 2013;42(9):1201-7. doi:10.1007/s00256-013-1657-9.

6. Hirschmann MT, Wagner CR, Rasch H, Henckel J. Standardized volumetric 3D-analysis of SPECT/CT imaging in orthopaedics: overcoming the limitations of qualitative 2D analysis. BMC Med Imaging 2012;12:5. doi:10.1186/1471-2342-12-5.

7. Schön SN, Afifi FK, Rasch H, Amsler F, Friederich NF, Arnold MP, et al. Assessment of in vivo loading history of the patellofemoral joint: a study combining patellar position, tilt, alignment and bone SPECT/CT. Knee Surg Sports Traumatol Arthrosc 2014;22(12): 3039-46. doi:10.1007/s00167-013-2698-2.

8. Mucha A, Dordevic M, Testa EA, Rasch H, Hirschmann MT. Assessment of the loading history of patients after high tibial osteotomy using SPECT/CT - a new diagnostic tool and algorithm. J Orthop Surg Res 2013;8(1):46. doi:10.1186/1749-799X-8-46.

9. Hirschmann MT, Schön S, Afifi FK, Amsler F, Rasch H, Friederich $\mathrm{NF}$, et al. Assessment of loading history of compartments in the knee using bone SPECT/CT: a study combining alignment and 99mTc-HDP tracer uptake/distribution patterns. J Orthop Res 2013;31(2):268-74. doi:10.1002/jor.22206.

10. Henderson IJ, Tuy B, Connell D, Oakes B, Hettwer WH. Prospective clinical study of autologous chondrocyte implantation and correlation with MRI at three and 12 months. J Bone Joint Surg $\operatorname{Br} 2003 ; 85(7): 1060-6$.

11. Ryd L, Gustafson T, Lindstrand A. 99mTc-diphosphonate scintigraphy in successful knee arthroplasty and its relation to micromotion. Clin Orthop Relat Res 1993;287:61-7.

12. Klett R, Steiner D, Laurich S, Bauer R, Kordelle J. Evaluation of aseptic loosening of knee prostheses by quantitative bone scintigraphy. Nuklearmedizin 2008;47(4):163-6.

13. Sacchetti GM, Ghisellini F, Brambilla M, De Consoli A, Fornara P, Rizzo E, et al. Quantitative scintigraphic evaluation of total knee arthroplasties: a feasibility study. Clin Orthop Relat Res 1996;325: $181-9$.

14. Saari T, Uvehammer J, Carlsson LV, Regnér L, Kärrholm J. Posterior stabilized component increased femoral bone loss after total knee replacement. 5-year follow-up of 47 knees using dual energy X-ray absorptiometry. Knee 2006;13(6):435-9. doi:10. 1016/j.knee.2006.08.002.

15. Soininvaara T, Nikola T, Vanninen E, Miettinen H, Kröger H. Bone mineral density and single photon emission computed tomography changes after total knee arthroplasty: a 2-year follow-up study. Clin 
Physiol Funct Imaging 2008;28(2):101-6. doi:10.1111/j.1475097X.2007.00782.x.

16. Windisch C, Windisch B, Kolb W, Kolb K, Grützner P, Roth A. Osteodensitometry measurements of periprosthetic bone using dual energy X-ray absorptiometry following total knee arthroplasty. Arch Orthop Trauma Surg 2012;132(11):1595-601. doi:10.1007/ s00402-012-1601-9.

17. Minoda Y, Ikebuchi M, Kobayashi A, Iwaki H, Inori F, Nakamura H. A cemented mobile-bearing total knee replacement prevents periprosthetic loss of bone mineral density around the femoral component: a matched cohort study. J Bone Joint Surg Br 2010;92(6): 794-8. doi:10.1302/0301-620X.92B6.23159.

18. Toegel S, Hoffmann O, Wadsak W, Ettlinger D, Mien LK, Wiesner $\mathrm{K}$, et al. Uptake of bone-seekers is solely associated with mineralisation! A study with 99mTc-MDP, 153Sm-EDTMP and $18 \mathrm{~F}$-fluoride on osteoblasts. Eur J Nucl Med Mol Imaging 2006;33(4):491-4. doi:10.1007/s00259-005-0026-x.

19. Li MG, Nilsson KG. No relationship between postoperative changes in bone density at the proximal tibia and the migration of the tibial component 2 years after total knee arthroplasty. J Arthroplasty 2001;16(7):893-900. doi:10.1054/arth.2001.24376.

20. Hirschmann MT, Davda K, Iranpour F, Rasch H, Friederich NF. Combined single photon emission computerised tomography and conventional computerised tomography (SPECT/CT) in patellofemoral disorders: a clinical review. Int Orthop 2011;35(5): 675-80. doi:10.1007/s00264-010-1049-x.

21. Hirschmann MT, Konala P, Iranpour F, Kerner A, Rasch H, Friederich NF. Clinical value of SPECT/CT for assessment of patients with painful knees after total knee arthroplasty - a new dimension of diagnostics? BMC Musculoskelet Disord 2011;12:36.

22. Ahmad R, Kumar GS, Katam K, Dunlop D, Pozo JL. Significance of a "hot patella" in total knee replacement without primary patellar resurfacing. Knee 2009;16(5):337-40. doi:10.1016/j.knee. 2009.02.001.

23. Hirschmann MT, Konala P, Amsler F, Iranpour F, Friederich NF, Cobb JP. The position and orientation of total knee replacement components: a comparison of conventional radiographs, transverse 2D-CT slices and 3D-CT reconstruction. J Bone Joint Surg Br 2011;93(5):629-33. doi:10.1302/0301-620X.93B5.25893.

24. Hirschmann MT, Iranpour F, Konala P, Kerner A, Rasch H, Cobb JP, et al. A novel standardized algorithm for evaluating patients with painful total knee arthroplasty using combined single photon emission tomography and conventional computerized tomography. Knee Surg Sports Traumatol Arthrosc 2010;18(7):939-44. doi:10. 1007/s00167-010-1070-Z.

25. Srivastava A, Lee GY, Steklov N, Colwell Jr CW, Ezzet KA, D'Lima DD. Effect of tibial component varus on wear in total knee arthroplasty. Knee 2012;19(5):560-3. doi:10.1016/j.knee. 2011.11.003.

26. Matsuda S, Whiteside LA, White SE. The effect of varus tilt on contact stresses in total knee arthroplasty: a biomechanical study. Orthopedics 1999;22(3):303-7.

27. Green GV, Berend KR, Berend ME, Glisson RR, Vail TP. The effects of varus tibial alignment on proximal tibial surface strain in total knee arthroplasty: the posteromedial hot spot. J Arthroplasty 2002;17(8):1033-9. doi:10.1054/arth.2002.35796.

28. Werner FW, Ayers DC, Maletsky LP, Rullkoetter PJ. The effect of valgus/varus malalignment on load distribution in total knee replacements. J Biomech 2005;38(2):349-55. doi:10.1016/j. jbiomech.2004.02.024.

29. Perillo-Marcone A, Taylor M. Effect of varus/valgus malalignment on bone strains in the proximal tibia after TKR: an explicit finite element study. J Biomech Eng 2007;129(1):1-11. doi:10.1115/1. 2401177.

30. Hofmann S, Romero J, Roth-Schiffl E, Albrecht T. Rotational malalignment of the components may cause chronic pain or early failure in total knee arthroplasty. Orthopade 2003;32(6):469-76. doi:10.1007/s00132-003-0503-5.

31. Fehring TK. Rotational malalignment of the femoral component in total knee arthroplasty. Clin Orthop Relat Res 2000;380:72-9.

32. Kuriyama S, Ishikawa M, Furu M, Ito H, Matsuda S. Malrotated tibial component increases medial collateral ligament tension in total knee arthroplasty. J Orthop Res 2014;32(12):1658-66. doi: 10.1002/jor.22711.

33. Kessler O, Lacatusu E, Sommers MB, Mayr E, Bottlang M. Malrotation in total knee arthroplasty: effect on tibial cortex strain captured by laser-based strain acquisition. Clin Biomech (Bristol, Avon) 2006;21(6):603-9. doi:10.1016/j.clinbiomech.2006.01.011.

34. Petersen MM, Olsen C, Lauritzen JB, Lund B. Changes in bone mineral density of the distal femur following uncemented total knee arthroplasty. J Arthroplasty 1995;10(1):7-11.

35. Petersen MM, Nielsen PT, Lebech A, Toksvig-Larsen S, Lund B. Preoperative bone mineral density of the proximal tibia and migration of the tibial component after uncemented total knee arthroplasty. J Arthroplasty 1999;14(1):77-81.

36. van Loon CJ, Oyen WJ, de Waal Malefijt MC, Verdonschot N. Distal femoral bone mineral density after total knee arthroplasty: a comparison with general bone mineral density. Arch Orthop Trauma Surg 2001;121(5):282-5.

37. Li MG, Nilsson KG. Changes in bone mineral density at the proximal tibia after total knee arthroplasty: a 2-year follow-up of 28 knees using dual energy X-ray absorptiometry. J Orthop Res 2000;18(1):40-7. doi:10.1002/jor.1100180107.

38. Lonner JH, Klotz M, Levitz C, Lotke PA. Changes in bone density after cemented total knee arthroplasty: influence of stem design. J Arthroplasty 2001;16(1):107-11. doi:10.1054/arth.2001.16486.

39. Hernandez-Vaquero D, Garcia-Sandoval MA, Fernandez-Carreira JM, Gava R. Influence of the tibial stem design on bone density after cemented total knee arthroplasty: a prospective seven-year follow-up study. Int Orthop 2008;32(1):47-51. doi:10.1007/ s00264-006-0280-y.

40. Boyd Jr AD, Ewald FC, Thomas WH, Poss R, Sledge CB. Longterm complications after total knee arthroplasty with or without resurfacing of the patella. J Bone Joint Surg Am 1993;75(5): 674-81.

41. Fitzpatrick CK, Baldwin MA, Ali AA, Laz PJ, Rullkoetter PJ. Comparison of patellar bone strain in the natural and implanted knee during simulated deep flexion. J Orthop Res 2011;29(2): 232-9. doi:10.1002/jor.21211. 